\title{
Chondroitin Sulphate and Gas Foaming Concurrently Improve Articular Cartilage Regeneration in Electrospun Poly(L-lactide-co- $\varepsilon-$ caprolactone)/Silk Fibroin Based Scaffolds
}

\section{Yujie Chen}

Donghua University - Songjiang Campus: Donghua University

\section{Wei Xu}

Weifang Medical College: Weifang Medical University

Muhammad Shafiq

Donghua University - Songjiang Campus: Donghua University

\section{Daiying Song}

Weifang Medical College: Weifang Medical University

\section{Xianrui Xie}

Donghua University - Songjiang Campus: Donghua University

\section{Zhengchao Yuan}

Donghua University - Songjiang Campus: Donghua University

\section{Mohamed EL Newehy \\ King Saud University}

\section{Hany EL Hamshary}

King Saud University

\section{Yosry Morsi}

Swinburne University of Technology

Yu Liu

Weifang Medical College: Weifang Medical University

Xiumei Mo ( $\nabla$ xmm@dhu.edu.cn )

Donghua University

\section{Research Article}

Keywords: Electrospun, Three-dimensional, Gas foaming, Chondroitin sulfate, Cartilage tissue engineering

Posted Date: August 24th, 2021 
License: (c) (i) This work is licensed under a Creative Commons Attribution 4.0 International License. Read Full License

Loading [MathJax]/jax/output/CommonHTML/jax.js 


\section{Abstract}

Degenerated cartilage tissues remain a burgeoning issue to be tackled, while bioactive engineering products available for optimal cartilage regeneration are scarce. In the present study, two-dimensional (2DS) poly(L-lactide-co-e-caprolactone)/silk fibroin (PLCL/SF)-based scaffolds were fabricated by conjugate electrospinning method, and then cross-linked with chondroitin sulfate (CS) to further enhance their mechanical and biological performance. Afterwards, three-dimensional PLCL/SF scaffolds (3DS) and CS-crosslinked three-dimensional scaffolds (3DCSS) with tailored size were successfully fabricated by in situ gas foaming in a confined mold and subsequently freeze-dried. Gas-foamed scaffolds exhibited high porosity, rapid water absorption, and stable mechanical properties. While all of the scaffolds exhibited excellent cytocompatibility in vitro; 3DCSS showed better cell seeding efficiency and chondroprotective effect as compared to the other scaffolds. Histological analysis of chondrocytes-seeded constructs after cultivation for up to 6 weeks in vitro also confirmed that 3DCSS scaffolds supported the formation of cartilage-like tissues along with the more secretion of cartilage-specific extracellular matrix than that of the other groups. The reparative potential of 3DCSS was further evaluated in an articular cartilage defect model in rabbits, which exhibited a well-integrated boundary and attenuated inflammation demonstrating less expression of pro-inflammatory cytokines, such as interleukin (IL)-1 $\beta$ and tumor necrosis factor (TNF)-a. Taken together, the engineered biomimetic 3DCSS may provide a wellsuited therapeutic option for cartilage tissue regeneration applications.

\section{Introduction}

Articular cartilage injuries, resulting from the acute or repetitive trauma, osteoarthritis and various other joint disorders, pose a substantial burden globally, which may cause permanent disability and discomfort [1]. Cartilage has a limited intrinsic healing capacity due to the lack of vascularization and innervation network as well as its isolation from the peripheral circulation. Therefore, cartilage injuries remain one of the most problematic diseases for orthopedic surgeons [2]. A variety of clinical approaches, such as drilling, mosaicplasty, microfracture, and autologous chondrocyte implantation (ACl), are proposed for restoring normal joint congruity and minimize further joint degeneration [3, 4]. However, none of these techniques has achieved success for the functional cartilage repair owing to the prior surgical procedures, less numbers of donors as well as the low elasticity and toughness of neo-cartilage tissues $[5,6]$. To overcome the clinical shortages of synthetic cartilage substitutes, cartilage tissue engineering (CTE), has been put forwarded [7].

Since scaffolds play a significant role in CTE, it is essential to engineer an ideal platform exhibiting characteristics, such as biocompatibility, biodegradability, and sufficient mechanical strength to support cell differentiation and matrix production [8]. Numerous strategies have been devised to afford CTE scaffolds, such as phase separation, 3D printing, and electrospinning; the latter has gathered significant attention of the research community owing to its applicability to a myriad of materials with high nanofiber production efficiency [9]. Nonetheless, the morphology of the membranes assembled from 
pores, preventing cellular infiltration necessary to form 3D tissues [10]. Conjugate electrospinning technology, which utilizes double metal spinnerets with opposing charges and forms nanoyarn scaffolds with a highly organized interior aligned structure, has been extensively researched to fabricate nanoyarn scaffold for annulus fibrosus or vascular tissue engineering [11]. Meanwhile, the simultaneous operation of two nozzles promotes the efficiency of the fabrication process. Although membranes assembled from conjugate electrospinning have achieved some improvements in the topological arrangement and porosity as compared to those fabricated by using conventional electrospinning, the fiber organization is still tightly-packed limiting cellular infiltration [12]. Thus, there is a dire need to devise strategies to convert 2D nanofibrous membranes into 3D-like porous structures.

An array of post-treatment methods, such as gas foaming, self-assembly of short fibers, and electrospraying have been proposed for transforming 2D membranes into 3D scaffolds [13, 14]. Amongst, gas foaming, which either utilizes gas bubbles generated in situ via a chemical reaction (e.g., the decomposition of sodium borohydride, $\mathrm{NaBH}_{4}$ ) or the addition of an inert gas, requires uncomplicated equipment, and can be used in almost all experimental settings, rendering it as an efficient method for fabricating 3D nanofiber matrices with layered structures $[15,16]$. Although gas-foaming has been widely exploited for fabricating porous scaffolds, the selection of the synthetic material in most of the cases, including the use of hydrophobic polymers, such as nylon, poly(vinylene difluoride) (PVDF), and polycaprolactone $(P C L)$ renders the scaffolds lacking cell recognition cues $[17,18]$. These scaffolds require further modification by plasma, or coating with extracellular matrix (ECM)-derived proteins to improve their hydrophilicity and cytocompatibility $[19,20]$. Yet in some seminal reports, natural and synthetic materials were combined to prepare hybrid gas-foamed scaffolds for wound healing or nerve regeneration, but how to improve their biological functionality, such as the induction of cell differentiation and promotion of specific cellular matrix secretion is still a challenge [21, 22]. It is known that the cartilage defect amplifies the inflammation in the joints, leading to an overproduction of proinflammatory mediators [23]. The establishment of a microenvironment that may promotes cartilage proliferation, maintains the cell phenotype as well as attenuates inflammation is therefore highly beneficial for cartilage regeneration. Furthermore, the control of the thickness of gas-foamed scaffold has not been paid sufficient attention; it is difficult to precisely control the size of the scaffolds merely by varying the concentration of the foaming medium or the processing time.

In this study, we designed chondroitin sulfate (CS)-crosslinked 3D poly(L-lactide-co-e-caprolactone)/silk fibroin (PLCL/SF) scaffolds (3DCSS) with accurate thickness and evaluated their potential for cartilage regeneration. SF enhances the hydrophilicity of the hybrid scaffold and can sustain cell proliferation, while also possesses a low inflammatory potential [24]. CS is the physiological component of the cartilage, possessing numerous useful merits, including anti-inflammatory activity, water and nutrients absorption, chondrogenic potential at cellular level that helps restore structure and function of the articular cartilage [25]. Briefly, 2D PLCL/SF nanofibrous scaffolds (2DS) were afforded by conjugate electrospinning, followed by crosslinking with the CS by using 1-ethyl-3-(3-dimethylaminopropyl) carbodiimide (EDC) and N-hydroxysuccinimide (NHS). Then, scaffolds were loaded into a manually Loading [MathJax]/jax/output/CommonHTML/jax.js 
fabricated mold and immersed into gas foaming solution (sodium borohydride, $\mathrm{NaBH}_{4}$ ) to obtain porous 3DCSS with tailored size. We hypothesize that 3DCSS scaffolds feature precise thickness, better biomechanical and biological properties, which concurrently encourage cellular infiltration, chondrification, cartilage-specific ECM matrix secretion, and inflammation resolution. After a thorough characterization, including the composition, morphology, mechanical properties, cytocompatibility, and inflammatory response, the scaffolds were investigated in terms of the chondro-inductivity for up to 6 weeks in an in vitro culture as well as in an in vivo articular cartilage defect model in rabbits (Fig. 1).

\section{Experimental \\ 2.1. Materials}

Poly(L-lactide-co- $\varepsilon$-caprolactone) (PLCL, $\mathrm{M}_{\mathrm{w}}=300 \mathrm{kDa}$, L-lactic acid to $\varepsilon$-caprolactone mole ratio, 50:50) was purchased by Jinan Daigang Biomaterial Co., Ltd. (Jinan, China). Hexafluoroisopropanol (HFIP) was obtained from Shanghai Darui Fine Chemical Co., Ltd. (Shanghai, China). Cocoon of B. mori silkworm was purchased from Huzhou Silk Co., Ltd. (Huzhou, China). Chondroitin sulfate sodium salt (CS, purity, $95 \%$, from porcine cartilage was obtained from Macklin Biochemical Co., Ltd. (Shanghai, China). Sodium borohydride (purity, $\geq 98 \%$ ) was purchased from Sinopharm Chemical Reagent Co., Ltd. (Shanghai, China). 2,2-diphenyl-1-picrylhydrazyl (DPPH) was purchased from Sinopharm Chemical Reagent Co. Ltd (Shanghai, China).

\subsection{Fabrication of two-dimensional nanofiber mats}

A purpose-built electrospinning device (SS-3556H, Ucalery, Beijing, China) with a double-nozzle conjugated electrospinning system was utilized to fabricate two-dimensional PLCL/SF scaffolds (2DS) as described previously [26]. PLCL and SF were dissolved in HFIP in a mass ratio of 8:2 at a total concentration of $10 \%(\mathrm{w} / \mathrm{v})$. The mixed solution was loaded into two oppositely positioned blunt-ended needle $10-\mathrm{mL}$ syringes pumped at a flow rate of $1.2 \mathrm{~mL} / \mathrm{h}$. A high-voltage with positive $(+12 \mathrm{kV})$ and negative $(-12 \mathrm{kV})$ static current was introduced on the needles of each side. During electrospinning process, the nanofibers carrying opposite charges were intertwined in the air, and a rotating circular drum (500 rpm) was placed between two jets to collect the arranged 2DS.

\subsection{Fabrication of 3D PLCL/SF scaffolds and CS- crosslinked scaffolds}

Prior to the fabrication of 3D PLCL/SF scaffolds (3DS), 2DS were cross-linked to improve the stability of membranes and submerged into $50 \mathrm{~mL}$ of mixed solution containing $50 \mathrm{mM}$ 2-morpholinoethanesulfonic acid (MES) buffer, $30 \mathrm{mM} \mathrm{EDC}$, and $8 \mathrm{mM} \mathrm{NHS}$ for up to $6 \mathrm{~h}$. The cross-linked membranes were washed with deionized water three times and then dried in a vacuum oven. Subsequently, 2DS were immersed into foaming agent (concentration: $0.5 \mathrm{M} \mathrm{NaBH}_{4}$ solution) and removed from the medium at predetermined time point. After rinsing three times with the deionized water and freeze-drying, the dried 
porous 3DS was obtained. The production of hydrogen bubbles from $\mathrm{NaBH}_{4}$ solution is based on the Eq. (1) (Eq. (1)):

$\mathrm{NaBH}_{4}+2 \mathrm{H}_{2} \mathrm{O} \rightarrow \mathrm{NaBO}_{2}+4 \mathrm{H}_{2} \uparrow(1)$

To obtain the CS-crosslinked 3D scaffolds (3DCSS), the same cross-linking agent as mentioned above was firstly prepared with the only difference that $1 \mathrm{~g}$ of CS was added into the mixed crosslinking agent. 2DS were immersed into the cross-linking medium containing CS for $6 \mathrm{~h}$. Subsequently, free CS and salt on the 2DS were washed with deionized water for three times. After drying, the CS cross-linked 2D membranes were treated with the above gas foaming method and subsequently processed (rinsed and freeze-dried) to afford 3DCSS.

For preparing 3D gas-foamed nanofiber scaffolds with precisely controllable thickness, a mold with predetermined height ( $3 \mathrm{~mm}$ ) was employed. Briefly, a concave mold made of hot-poured Teflon was used as a base, and a matching-sized glass was then covered and adhered to the base by using light-curing glue. The electrospun nanofiber mat was placed at the center of the mold and immersed into the $\mathrm{NaBH}_{4}$ solution as described above. After half an hour, the holder was removed and rinsed thrice with deionized water. After freeze-drying, 3DS or 3DCSS with precise thickness were obtained.

\subsection{Characterization}

The bulk volume of samples was measured by ethanol displacement method [18]. The volume percentage of specimens was then calculated by dividing volume of the gas foamed scaffold at different time intervals with the volume of the initial membrane. The bulk density of specimens was calculated by dividing the specimen mass with the bulk volume. The porosity of the nanofiber membranes and expanded scaffolds was measured by the liquid displacement method and calculated according to Eq. (2) [27]:

$$
P(\backslash \%)=\frac{W s(g)-W d(g)}{r\left(g / \mathrm{cm}^{3} \square \times V \square \mathrm{cm}^{3} \square\right.} \times 100 \backslash \%
$$

where $\mathrm{P}$ is the porosity, Ws is the weight of the sample after soaking for up to $10 \mathrm{~min}$ in ethanol with a density of ' $r$ ', Wd is the weight of the dry scaffold, and V is the volume of the sample $(n=3)$.

The photographs of 2D and 3D gas-foamed scaffolds were recorded by a digital camera. Samples were mounted on an aluminum stub with carbon tape and then sputter-coated with Au. Scanning electron microscopy (SEM, Phenom XL, Phenom Scientific Instruments Co. Ltd., Shanghai, China) was then used to observe the morphology of different scaffold. Subsequently, the surface morphology of nanofibers and cross-sections of different samples were imaged at an accelerating voltage of $10 \mathrm{kV}$. SEM images were analyzed by using Image $\mathrm{J}$ software to measure the pore area and gap distance of scaffolds. For pore 
area measurement $(n=20)$, the side length of the different shaped (triangular and diamond) holes was first measured, and then the area was calculated.

The elements on the surface of 3DCSS were analyzed by an energy dispersive spectrometer (EDS, JSM$7500 \mathrm{~F}$, China). Structural elucidation of scaffolds was carried out by using Fourier transform infrared spectroscopy (FTIR) by using a Nicolet-6700 FTIR spectrometer (Thermo Fisher Scientific, USA) in the range of $3800-600 \mathrm{~cm}^{-1}$.

The antioxidant activity of different samples was assessed by 2,2-diphenyl-1-picrylhydrazyl (DPPH) assay. Briefly, $10 \mathrm{mg}$ of each sample was mixed with $3 \mathrm{~mL}$ of $0.1 \mathrm{mM} \mathrm{DPPH} /$ ethanol solution, while protected from the light at room temperature. After reacting for $0.5 \mathrm{~h}$, the absorbance of each mixture was measured at $517 \mathrm{~nm}$ using ethanol as the blank. Pure ascorbic acid (AA) was used as a positive control. Whereas, DPPH solution without samples was taken as a blank. Radical scavenging activity was expressed as the scavenging rate and calculated by using the following Eq. (3):

$A(\%)=\left(A_{B}-A_{S}\right) / A_{B} \times 100 \%(3)$

Where $A$ is the $D P P H$. scavenging rate; $A_{B}$ and $A_{S}$ are the absorbance of the blank and experimental samples, respectively.

The water absorption capacity of different samples was determined according to the previous report [28]. The dry sample with known weights $\left(\mathrm{w}_{\mathrm{d}}\right)$ was added into a $25 \mathrm{~mL}$ flask containing $20 \mathrm{~mL}$ of phosphate buffered saline (PBS, $\mathrm{pH}=7.4$ ) solution at room temperature for up to $2.5,5$, and $15 \mathrm{~min}$. Afterwards, the excess water was absorbed from the scaffolds with a filter paper and the weight of the scaffold was recorded $\left(w_{w}\right)$. The water absorption rate $(w)$ was calculated according to Eq. (4):

$w=\left(w_{w}-w_{d}\right) / w_{d} \times 100 \%(4)$

The mechanical properties of scaffolds, including uniaxial tensile testing and compressive testing of samples were measured at room temperature by using a universal materials tester (Instron-5542, Canton, USA). Rectangular-shaped specimens of 2DS $(40 \mathrm{~mm} \times 10 \mathrm{~mm} \times 0.5 \mathrm{~mm}), 3 \mathrm{DS}(40 \mathrm{~mm} \times 10 \mathrm{~mm} \times 3$ $\mathrm{mm})$ and 3DCSS $(40 \mathrm{~mm} \times 10 \mathrm{~mm} \times 3 \mathrm{~mm})$ were evaluated by tensile testing in wet state. A cross-head speed of $5 \mathrm{~mm} / \mathrm{min}$ was used for all of the specimens examined until breakage point. For the compression test, rectangular-shaped samples with a side length of $10 \mathrm{~mm}$ and a thickness consistent with that described above were evaluated at a cross-head speed of $1 \mathrm{~mm} / \mathrm{min}$. The stress-strain curves of specimens were drawn by using the data recorded by the machine. Ultimate tensile strength (UTS) and elongation at break (Eb) were determined. The Young's moduli $(E)$ and compressive moduli of scaffolds were calculated analytically by using a slope fitting method of the initial linear region of the stress-strain curves.

\subsection{Evaluation of the biocompatibility of scaffolds in vitro}


Articular cartilage was derived from New Zealand white rabbit with an approval obtained from the Shanghai Pulmonary Hospital Ethics Committee and chondrocytes were isolated as previously reported [29]. The acquired chondrocytes were cultured, and expanded in the culture medium (high glucose, Dulbecco's modified Eagle's medium (DMEM, Gibco, USA) supplemented with $10 \%$ fetal bovine serum (FBS, Hyclone, USA) and $1 \%$ penicillin/streptomycin/amphotericin B solution in an incubator at $37^{\circ} \mathrm{C}[30]$. Chondrocytes at the second passage were used for the subsequent in vitro evaluations.

After sterilization by ultraviolet (UV) light for up to $6 \mathrm{~h}, 2 \mathrm{DS}, 3 \mathrm{DS}$ and 3DCSS were fixed in the bottom of the 24-well plate, and chondrocytes at a density of $3.0 \times 10^{4}$ cells in $500 \mu \mathrm{L}$ of medium were evenlyseeded onto each sample. After culturing for up to $24 \mathrm{~h}$, scaffolds were washed with PBS thrice and treated with live/dead staining kit (In vitrogen, USA). After washing, the fluorescence of cells was observed by using a confocal laser scanning microscope (Nikon, A1RMP, Japan).

The cell seeding efficiency of different scaffolds was analyzed as described previously [31]. The same cell density as above was evenly-dropped onto the materials. After an incubation for up to $4 \mathrm{~h}$, the media from different samples containing unseeded cells were collected and counted (lost cell number). The cell seeding efficiency of different scaffolds was calculated based on Eq. (5):

$$
\text { Cellseedingefficiency }(\%)=\frac{\text { totalcellnumber }- \text { lostcellsnumber }}{\text { totalcellnumber }} \times 100 \backslash \%(5)
$$

The proliferation of chondrocytes on scaffolds was determined by a cell counting kit 8 (CCK-8) assay. Chondrocytes $\left(3.0 \times 10^{4}\right)$ were seeded on 2DS, 3DS, and 3DCSS for up to 1,3 , and 7 days in a 24-well plate. At each time point, the medium was removed and the scaffolds were washed with PBS thrice. After that, $200 \mu \mathrm{L}$ of the CCK-8/DMEM mixture $(1: 10 \mathrm{v} / \mathrm{v})$ was added to each well and incubated for up to $2 \mathrm{~h}$ at $37^{\circ} \mathrm{C}$, the absorbance was measured at the wavelength of $450 \mathrm{~nm}$.

To observe the cell morphology and cell infiltration at pre-determined time points, chondrocytes grown on 2DS, 3DS and 3DCSS were fixed and dehydrated with an ascending series of graded ethanol (30-100\%). The morphology of chondrocytes was examined by SEM. Dehydrated cell seeded samples were paraffinembedded, sectioned $(5 \mu \mathrm{m})$ and stained by hematoxylin and eosin (H\&E). Chondrocyte infiltration was imaged by an optical microscope (Leica Microsystems, Germany).

The feasibility of scaffolds in promoting chondrogenesis in vitro was further evaluated by combining them with auricular chondrocytes. Firstly, $200 \mu \mathrm{L}$ of chondrocyte suspension at a concentration of $3.0 \times 10^{8}$ cells $/ \mathrm{mL}$ was seeded onto 2DS (diameter, $6.5 \mathrm{~mm}$ and thickness, $0.5 \mathrm{~mm}$ ), 3DS and 3DCSS (dimeter, $6.5 \mathrm{~mm}$ and thickness, $3 \mathrm{~mm}$ ). Subsequently, these cell-scaffold constructs were incubated at $37^{\circ} \mathrm{C}$ under $5 \% \mathrm{CO}_{2}$ for $2 \mathrm{~h}$ and then cultured in pre-warmed chondrogenic medium for up to 6 weeks in vitro. The chondrogenic medium used in this article is consistent with that of the previous study [32], and changed every 3 days during the culture duration. After 6 weeks, the chondrocyte-scaffold constructs were fixed in $4 \%$ Paraformaldehyde (PFA) and stained with H\&E and Safranin-O for histological analysis Loading [MathJax]/jax/output/CommonHTML/jax.js e engineered neocartilage tissues. Collagen type II was 
detected by immunohistochemical staining by following a previous method [33]. The specimens $(n=3)$ were minced to perform cartilage-related biochemical evaluations for DNA, glycosaminoglycan (GAG), and total collagen content as quantified by the PicoGreen dsDNA assay (Invitrogen), dimethylmethylene blue assay (Sigma-Aldrich), and hydroxyproline assay (Sigma-Aldrich) [34]. To determine the compressive moduli of cell-scaffold constructs $(n=3)$, a biomechanical testing machine (Instron-5542, Canton, USA) was used. Samples were subjected to unconfined compression tests at a strain rate of $1 \mathrm{~mm} / \mathrm{min}$ until they reached $50 \%$ compressive strain. The compressive moduli of tested samples were calculated based on the slopes of the generated stress - strain curves.

To explore the changes in the inflammatory response and compare the chondro-protective ability of different scaffolds, chondrocytes were seeded on 2DS, 3DS, and 3DCSS in a 6-well plate with a density of $3.0 \times 10^{5}$ cells/well and treated with interleukin-1 beta $(\mathrm{IL}-1 \beta, 10 \mathrm{ng} / \mathrm{mL})$ for up to $24 \mathrm{~h}$. Real-time quantitative polymerase chain reaction (RT-qPCR) was performed to analyze the expression of proinflammatory genes, including tumor necrosis factor-alpha (TNF-a), IL-1 $\beta$, matrix metalloproteinase-13 (MMP13). Cell-laden scaffolds $(n=3)$ were ground within TRIzol reagent (Invitrogen, Life Technologies) to extract total mRNA. About $1 \mu \mathrm{g}$ of RNA was used for cDNA synthesis by M-MLV cDNA Synthesis Kit (Promega) according to the manufacturer's instruction. RT-qPCR was performed by using SYBR Green PCR Master Mix (Enzynomics) and ABI StepOnePlus ${ }^{\text {TM }}$ Real-Time PCR system (Applied Biosystems). All primer sequences are listed in Table S1 (supplementary information). The expression of all genes was normalized to glyceraldehyde 3-phosphate dehydrogenase (GAPDH) and to gene expression of chondrocytes before seeding into the different samples and the relative expression was calculated by $2^{\Delta \Delta C t}$ method.

Immunofluorescence staining for the IL- $1 \beta$ and TNF- $\alpha$ was performed on sectioned slices of cell-seeded samples. Sections were incubated with anti-IL-1 $\beta$ (Abcam; 1:100 dilution) and anti-TNF-a (Abcam; 1:100 dilution) antibodies at $4^{\circ} \mathrm{C}$ overnight. After washing thrice with $0.1 \%$ bovine serum albumin (BSA)/PBS, sections were incubated with fluorescent-labeled secondary antibodies (Alexa-Fluor 546 or 488; Abcam; 1:200 dilution). The nuclei were stained with DAPI for $5 \mathrm{~min}$ at room temperature. Imaging was carried out by using a fluorescence microscope (Leica Microsystems, Germany).

\subsection{Assessment of articular cartilage regeneration in rabbits}

All animals were performed according to the standard guidelines approved by the ethics committee of Shanghai Jiao Tong University (SJTU). To determine the articular cartilage regeneration capability of engineered scaffolds, 2DS, 3DS, and 3DCSS were prepared prior to surgery. Adult healthy male New Zealand white rabbits, 4 months old and weighing approximately $2.5 \mathrm{~kg}$ were randomly selected and divided into three groups ( $n=4$ per group). After anesthesia with $10 \%$ of chloral hydrate, cartilage defects ( $4 \mathrm{~mm}$ in diameter and $3 \mathrm{~mm}$ in depth) were created by using a stainless-steel punch on the trochlear groove of the distal femur. 2DS (diameter, $4 \mathrm{~mm}$ and thickness, $0.5 \mathrm{~mm}$ ) and matching 3DS as well as 
3DCSS (diameter, $4 \mathrm{~mm}$ and thickness, $3 \mathrm{~mm}$ )) were implanted into the defects. Finally, surgical incisions were closed with sutures. All the rabbits were sacrificed at 12 weeks to harvest the knee joint.

Then, the harvested rabbit articular cartilages were firstly observed and scored according to International Cartilage Repair Society (ICRS) macroscopic scoring standard. Then, cartilage samples were decalcified, sectioned, and characterized for histological and further immunohistochemical analysis including $\mathrm{H} \& \mathrm{E}$, Safranin-O/ fast green (Safranin-O/FG), and collagen type I/II staining [33]. Furthermore, the regenerated cartilage was also assessed with Modified O'Driscoll histological scoring and Mankin score. The grading and scoring criteria are shown in the Table S2 - S4 (supplementary information). Immunofluorescence staining for IL-1 $\beta$ and TNF- $\alpha$ was performed on sectioned slices of different groups and the procedures was the same as in Sect. 2.5. The synovial fluid was collected by using a $2 \mathrm{~mL}$ syringe with an 18-gauge needle and centrifuged at $4000 \mathrm{rpm}$ for $20 \mathrm{~min}$ at $4^{\circ} \mathrm{C}$. The supernatants were collected and frozen at $-80^{\circ} \mathrm{C}$. IL-1 $\beta$ and TNF-a were assayed by enzyme-linked immunosorbent assay (ELISA), Rabbit IL-1 ELISA Kit and Rabbit TNF-a ELISA Kit; Abcam) according to the manufacturer's instructions.

\subsection{Statistical analysis:}

Experimental data are presented as mean \pm standard deviation (SD). For statistical significance, Student's $t$ test or one-way analysis of variance (ANOVA) with Tukey's post-hoc test was performed where appropriate confidence level. A p values $<0.05$ was considered to be statistically significant $\left({ }^{\star} p<0.05\right.$, $\star \star p<0.01, * \star \star p<0.001)$.

\section{Results}

\subsection{Fabrication and characterization of 2DS, 3DS and 3DCSS}

According to the schematic diagram shown in Fig. 1, the fabrication process of 2DS, 3DS, and 3DCSS scaffold can be mainly divided into the four steps: (1) conjugate electrospinning, (2) cross-linking, (3) gas foaming in a confined mold, and (4) freeze-drying. The fabrication of 3D scaffolds is simple and efficient, which is envisaged to be applied to the large-scale industrial process.

After treatment with $\mathrm{NaBH}_{4}$ solution for 5 min, the original mats were gradually expanded and the thickness of 3DCSS increased faster than that of the 3DS (Fig. 2A - B). The thickness of 3DS increased from $0.5-4 \mathrm{~mm}$ (Fig. 2C), while it increased from $0.5-8 \mathrm{~mm}$ for 3DCSS (Fig. 2D). The effect of the gas foaming time on the volume expansion, porosity, and density of the expanded scaffolds was investigated in detail. As shown in Fig. 2E, after 5 min of gas foaming, the volume of the 3DS and 3DCSS was 8 and 18 times larger than that of the unexpanded membranes. The bulk density of the 2D mats was 0.27 $\mathrm{g} / \mathrm{cm}^{3}$, which decreased to 0.03 and $0.02 \mathrm{~g} / \mathrm{cm}^{3}$ for 3DS and 3DCSS, respectively (Fig. 2F). Similarly, the porosity increased from 71-92 \% and 69-97 \% for 3DS and 3DCSS after gas foaming, respectively (Fig. 2G). To precisely control the thickness of the 3D scaffold, a mold consisting of a Teflon concave 
substrate assembled with a matching-sized glass piece was used. Due to the limitation in the height of the mold, the 3D scaffolds stopped expanding when they reached a certain thickness during the foaming process. After freeze-drying, a 3D nanofiber scaffold with a stable and pre-defined thickness was obtained (Fig. 3A). The direction of alignment of scaffolds is shown in Fig. 3B, in which the red arrow indicates the alignment direction of the nanofibers. Figure 3C exhibited the gross appearance of 2DS with a thickness of $0.5 \mathrm{~mm}$. After expansion in the mold, 3DS and 3DCSS with precise thickness $(3 \mathrm{~mm})$ were obtained and the photographs were shown in Fig. 3G and Fig. 3K, respectively. 2DS showed compactpacked structure of the cross-section (Fig. 3D - E) and densely aligned nanofibers and yarns of the surface (Fig. 3F). After expansion, good interconnectivity and continuous layered structure was achieved in 3DS (Fig. 3H - I) and 3DCSS (Fig. 3L - M). In addition, a loose surface with preserved aligned nanofibrous topographical cues was formed in 3D gas-foamed scaffolds (Fig. 3J \& N).

The cross-sectional gap distance was quantified for three types of scaffolds. Prior to the gas foaming, most of gap distances in 2DS were around 3-4 $\mu \mathrm{m}$ (Fig. 30), which increased to approximately 30-50 $\mu \mathrm{m}$ in 3DS and 30-60 $\mu \mathrm{m}$ in 3DCSS, respectively (Fig. 3P-Q). Moreover, the surface pore areas of 3DS $\left(64 \pm 20 \mu \mathrm{m}^{2}\right)$ and $3 \mathrm{DCSS}\left(62 \pm 24 \mu \mathrm{m}^{2}\right)$ were larger than that of the unexpanded 2DS $\left(17 \pm 5 \mu \mathrm{m}^{2}\right)(\mathrm{Fig}$. S1).

The elements on the surfaces of 3DCSS were analyzed by SEM equipped with EDS. The sulfur elements contained in the CS were evenly distributed on the fiber surface of the 3DCSS (Fig. 4A-C). The composition of different samples was further investigated by FTIR and the spectra in the range of 3800$600 \mathrm{~cm}^{-1}$ and $2200-600 \mathrm{~cm}^{-1}$ are shown in Fig. 4D-E. A strong and wide band at $3435 \mathrm{~cm}^{-1}$ was assigned to the $\mathrm{O}-\mathrm{H}$ and $\mathrm{N}-\mathrm{H}$ stretching vibration. The band at $2930 \mathrm{~cm}^{-1}$ was assigned to $\mathrm{C}-\mathrm{H}$ stretching vibration, while the shoulder at $1635 \mathrm{~cm}^{-1}$ corresponded to the carboxylic $(-\mathrm{COOH})$ groups. Additionally, the stretching vibration of $S=0$ of the sulfate groups of the CS was observed at $1255 \mathrm{~cm}^{-1}$ [35]. The representative band at $3295 \mathrm{~cm}^{-1}$ of $2 \mathrm{DS}$ corresponded to the $\mathrm{N}-\mathrm{H}$ stretching vibration of $\mathrm{SF}$, and the bands observed at $1645 \mathrm{~cm}^{-1}$ and $1540 \mathrm{~cm}^{-1}$ corresponded to the amide I and amide $\nabla$ bonds, respectively. An absorption band at $2938 \mathrm{~cm}^{-1}$ was ascribed to the $-\mathrm{CH}_{2}-$ stretching vibration of PLCL. Besides, PLCL exhibited a characteristic band at $1756 \mathrm{~cm}^{-1}$, which is ascribed to the stretching vibration of carbonyl groups of esters. Besides, significant absorption bands appeared at $1454 \mathrm{~cm}^{-1}$ and 1359 $\mathrm{cm}^{-1}$, corresponding to the $\mathrm{C}-\mathrm{H}$ symmetric and asymmetric vibrations, respectively. 3DS scaffolds also exhibited characteristic peaks of SF and PLCL, indicating that no other chemical interaction occurred during the gas foaming and freeze-drying processes. The representative bands of PLCL and SF were also exhibited in the 3DCSS spectrum. The band at $3435 \mathrm{~cm}^{-1}$ observed in 3DCSS corresponded to the stretching vibrations of $\mathrm{O}-\mathrm{H}$ in the $\mathrm{CS}$. The new amide bond formed by the carboxyl groups of the $\mathrm{CS}$ and the amino group $\left(-\mathrm{NH}_{2}\right)$ of the SF by EDC/NHS coupling, which was confirmed by the shift of the peak of amide bond II from $1540 \mathrm{~cm}^{-1}$ toward $1553 \mathrm{~cm}^{-1}[36,37]$. Moreover, an additional carbonyl peak at 1635 $\mathrm{cm}^{-1}$ in the 3DCSS spectrum near amide I further indicated the presence of CS in the 3DCSS. Taken 
together, the FTIR spectra confirmed the presence of the incorporated components into the scaffolds as well as their crosslinking with the CS.

The antioxidant activity of PLCL, 2DS, 3DS and 3DCSS was analyzed by using DPPH radical scavenging assay. Ascorbic acid was taken as a standard antioxidant agent. The results were shown in Fig. 4F. The antioxidant activity was found to be $82.49 \pm 1.49,3.59 \pm 1.90,28.29 \pm 2.52,40 . .04 \pm 3.96$ and $62.35 \pm 6.68$ (\%) for ascorbic acid, PLCL, 2DS, 3DS, and 3DCSS, respectively.

Figure 4G exhibited the representative stress-strain curves of 2DS, 3DS and 3DCSS characterized by tensile measurement. The Young's modulus $(E)$, UTS, and Eb of all samples were also summarized (Fig. 4H-J). 2DS exhibited better tensile performance than that of 3D gas foamed scaffolds with $E$, UTS, and Eb values of $2.22 \pm 0.12 \mathrm{MPa}, 4.31 \pm 0.21 \mathrm{MPa}$, and $139.21 \pm 4.74 \%$, respectively. The $E$ of 3DCSS $(0.63 \pm 0.04 \mathrm{MPa})$ was higher than that of $3 \mathrm{DS}(0.33 \pm 0.07 \mathrm{MPa})$. However, both types of scaffolds did not significantly differ in terms of the UTS and Eb (3DS, UTS, $0.42 \pm 0.05 \mathrm{MPa} \& \mathrm{~Eb} 112.96 \pm 12.16 \%$ and 3DCSS, UTS, $0.59 \pm 0.04 \mathrm{MPa} \&$ Eb $104.43 \pm 11.07 \%$ ). Both types of gas-foamed groups exhibited nonlinear closed compressive stress-strain curves (Fig. 4L), and the compressive modulus was found to be $1.23 \pm 0.26 \mathrm{kPa}$ and $1.99 \pm 0.16 \mathrm{kPa}$ for $3 \mathrm{DS}$ and 3DCSS, respectively (Fig. 4K). The maximum water absorption of 3DS and 3DCSS scaffolds $(\approx 1800 \%)$ was reached within 5 minutes, and was significantly higher than that of the 2DS $(\approx 500 \%)$ (Fig. S2).

\subsection{In vitro cytocompatibility studies}

Live/Dead staining assay was used to detect cell viability in the constructs. Both 2D and 3D gas-foamed scaffolds showed minimal cell cytotoxicity with well-proportioned distribution of chondrocytes after $24 \mathrm{~h}$ of culture under a confocal microscope. More chondrocytes survived on the 3D gas-foamed scaffolds than that of the 2DS groups. The morphology of attached chondrocytes at day 5 was observed by SEM. Chondrocytes integrated well with the scaffolds in all three groups and proliferated along the nanofibers (Fig. 5D - F). Cell infiltration, assessed by H\&E staining, indicted more numbers of cells infiltrated into the 3D gas-foamed scaffolds compared to 2DS (Fig. 5G - I). Moreover, 3D gas-foamed scaffolds presented considerably better cell seeding efficiency after $4 \mathrm{~h}$ of culture than 2DS (Fig. 5S).

Cell proliferation was determined by CCK-8 assay, which demonstrated that all nanofiber scaffolds had good cell viability in vitro (Fig. 5T). On days 1 to 7 , the proliferation of chondrocytes on the 3D gasfoamed scaffolds was significantly higher than of the 2DS. Notably, at day 7, the 3DCSS showed highest numbers of cells among all of the investigated groups. These results reveal that 3DCSS could provide a conducive environment for cell growth and infiltration in vitro, which may also have implications for the in vivo applications.

\subsection{In vitro evaluation of cartilage regeneration}

To further validate the regenerative ability of engineered scaffolds in vitro, chondrocytes were evenly dropped onto different scaffolds and grown for up to 6 weeks. All of the scaffolds, maintained their 
Histological analysis demonstrated that all of the groups contained the cartilage-specific ECM deposition (Fig. 5M - 0). 2DS and 3DS specimens exhibited positive staining for Safranin-O and collagen type II only in some regions of the regenerated cartilage (Fig. 5P-Q \& Fig. S3A-B). Intriguingly, 3DCSS exhibited a relatively dense and homogeneous distribution of cartilaginous tissues than that of the other groups (Fig. 5R \& Fig. S3C). Moreover, the quantitative analysis showed that the compressive modulus, DNA content, total GAG content, and collagen content were higher in 3DCSS as compared to the other groups, indicating the 3DCSS were better for the regeneration of matured cartilage as well as cartilage-specific matrix production (Fig. $5 \mathrm{U}-\mathrm{X}$ ).

\subsection{In vitro evaluation of anti-inflammatory effect}

To confirm the chondro-protective ability of different scaffolds, chondrocytes were seeded on scaffolds and treated with IL-1 $\beta$ to mimic the inflammatory microenvironment after injury. Immunostaining results showed the expression of IL-1 $\beta$ and TNF- $\alpha$ was more prominent in 2DS and 3DS groups compared to the weak staining of the 3DCSS group (Fig. 5Y). The inflammatory gene expressions were also evaluated by RT-qPCR (Fig. 5Z). As anticipated, the inflammatory genes, such as IL-1 3 , TNF- $\alpha$ and MMP13 were only marginally expressed in the 3DCSS group than that of the other groups, confirming the better antiinflammatory effect of 3DCSS in vitro.

\subsection{In vivo evaluation of articular cartilage regeneration}

Cartilage regeneration in vivo was a crucial criterion to determine the appropriateness of the scaffold for CTE. A rabbit articular cartilage defect model was used to assess the therapeutic efficacy of 2DS, 3DS and 3DCSS. After implantation for up to 12 weeks, the gross appearance of retrieved articular tissues was observed and compared. The cartilage defects in the 2DS groups were clearly visible, indicating the poor integration of the scaffolds with the normal cartilage tissues (Fig. 6A). In contrast, the defects in the 3DS group were only partially covered by the newly-formed cartilage-like tissues (Fig. 6B). Notably, 3DCSS group achieved a best regeneration outcome, as the defect was filled with neo-cartilage, and the boundary between defect site and surrounding cartilage was almost invisible (Fig. 6C).

H\&E staining and Safranin O-fast green staining assays of the retrieved cartilage samples were further performed to examine the formation of fibrous tissue, and the deposition of ECM. In 2DS groups, an irregular border between the neo-tissues and native cartilage was observed and only fibrous tissues were detected in the joint, where only a few unevenly distributed cartilage clusters filled the defect (Fig. 6D \& D1). For the 3DS, a thin layer of cartilage-like tissue was observed on the surface of the defect region, whereas some fibrous tissues containing fewer cells were found (Fig. 6E \& E1). By contrast, the 3DCSS groups displayed a well-integrated boundary filled with homogeneously distributed newly formed tissues featured with the chondrocyte-specific lacunas (Fig. 6F \& F1).

2DS group also lacked Safranin O-fast green staining in the defect region (Fig. 6G \& G1). For 3DS groups newly formed tissue with a weak staining for the Safranin O-fast green filled the defect region (Fig. $6 \mathrm{H} \&$ H1). These results indicated that 2DS and 3DS groups exhibited fibrous tissue, which lacked the

Loading [MathJax]/jax/output/CommonHTML/jax.js contrast, in 3DCSS groups, it was shown that the defect area 
was covered with a large amount of positively-stained cartilage ECM, indicating the formation of matured cartilage as well as the deposition of the abundant GAGs (Fig. 6I \& I1). Consistent with the histological staining trends, the immunohistochemical analysis of the collagen type II exhibited a significant deposition of the collagen type II (Fig. 6L \& L1) in 3DCSS groups compared to only a limited and slight deposition of collagen in the 2DS (Fig. 6J \& J1) and 3DS groups (Fig. 6K \& K1). Moreover, the 3DCSS groups showed only a weak staining for the collagen type I than that of the 2DS and 3DS groups. The collagen type I seemed to be the dominant form in the newly formed tissues in the defects treated with the 2DS as well as a few regions of 3DS groups (Fig. S4). All of these results demonstrated that 3DCSS achieved a satisfactory regeneration of cartilage along with the accumulation of the cartilage-specific ECM rather than the fibrocartilage formation.

To evaluate the quality of the regenerated cartilage, the results of ICRS macroscopic score (a total 12 points), modified O'Driscoll histological score (a total 24 points) and Mankin score (a total 14 points) were summarized. 3DCSS groups showed better ICRS macroscopic score $(10.2 \pm 0.9)$, significantly higher than that of the 3DS $(7.0 \pm 0.8)$, and 2DS groups (5.2 \pm 0.9$)$ (Fig. 6M). A similar trend was observed in the modified O'Driscoll histological scoring, in which 3DCSS exhibited the higher score $(20.5 \pm 1.9)$ than that of the other two groups ( $14.0 \pm 1.8$ for 3DS and $9.7 \pm 1.5$ for 2DS) (Fig. $6 \mathrm{~N}$ ). Mankin score further indicated the best repair outcome in 3DCSS group ( $2.75 \pm 0.5)$ compared to 3DS $(5 \pm 1.15)$ and 2DS (7.75 $\pm 0.95)$ (Fig. 60).

The intra-articular inflammatory response was discerned by immunofluorescent staining for different types of inflammatory markers, which demonstrated a high expression of IL-1 $\beta$ and TNF-a in the 2DS group as compared to the other groups. Similar to the native cartilage, weak fluorescent expression of pro-inflammatory markers was observed in 3DCSS groups (Fig. 7A). Meanwhile, quantification results of inflammatory factors, such as IL-1 $\beta$ and TNF- $\alpha$, showed the less expression of inflammatory markers in the 3DCSS groups compared to the 2DS and 3DS groups, indicating that 3DCSS attenuated the inflammatory response and provided conducive environment for neo-cartilage formation (Fig. 7B-C).

\section{Discussion}

Electrospinning, as a universal and cost-effective nanofiber fabrication technology, has been extensively explored for developing tissue engineering scaffolds and devices for a myriad of clinical and industrial applications [38]. However, it is known that 2D nanofiber membranes generated by conventional electrospinning pose certain restrictions for cell infiltration due to their tightly-packed layers and dense superficial pores, which lack 3D-like architecture for tissue regeneration. Recent studies reported numerous attempts to afford 3D tissue-engineered scaffolds with nanofibrous structures based on 3D printing or self-assembly of short nanofibers as well as self-folding nanofiber mats $[31,39,40]$. Besides, it has been reported that the porosity and pore size of electrospun scaffolds can be tailored by varying the fiber size $[41,42]$. These technologies are limited by some constraints, such as exposure of the scaffolds to the toxic solvents, lengthy and time-consuming preparation procedures as well as the requirement of 
the post-treatment of electrospun nanofiber membranes to afford 3D nanofiber scaffolds. Gas foamed scaffolds often feature laminated fibrous layered structure with high porosity and interconnected pores, providing sufficient space and a stable 3D-like architecture for cell infiltration and proliferation $[15,17]$. However, to the best of the authors knowledge, most of the gas-foamed scaffolds have been assembled from synthetic polymers, such as poly(caprolactone) $(\mathrm{PCL})$, poly(L-lactide-co-e-caprolactone) ( $\mathrm{PLCL})$, or poly(L-lactide) (PLLA), which lack cell recognition cues, and necessitate post-modification with ECMderived proteins or peptides for tissue repair applications. Moreover, merely by adjusting the physical parameters, such as time or the concentration of the foaming agent to afford scaffolds with the controlled structure and size may not hold considerable potential to afford uniform expansion throughout the scaffold, especially in the central region $[19,43]$. To overcome these limitations, herein, we have realized bio-hybrid scaffolds composed of natural and synthetic polymers, namely, SF and PLCL which exhibited good hydrophilicity and biocompatibility. By cross-linking with CS and gas-foaming, the cell infiltration and pro-chondrogenic potential of expanded porous scaffolds was augmented leading to the better cartilage regeneration both in vitro and in vivo.

Appropriate choice of the materials is the basis for the successful preparation of 3D nanofiber scaffolds. PLCL, a synthetic copolymer with mechano-elastic and biodegradable properties, imparts stable mechanical structure and extensibility to the hybrid scaffold; however, it lacks effective cell recognition sites due to its hydrophobic nature [44]. Silk fibroin, a protein-based natural polymer may contain ligands that can be recognized by the cell-surface receptors, which may improve the biocompatibility and reduce the regulatory constraints $[7,45]$. As a favorable natural materials, SF exhibits unique properties, such as good biocompatibility and biodegradability, which may also increase the hydrophilicity of the scaffold materials [46]. Apart from the aforementioned advantages, SF is less risky in terms of the infection compared to the other proteinaceous materials [11]. Hence, a blend of PLCL and SF was employed for the fabrication of scaffold, which has already been exploited for the regeneration of other types of tissues, such as tendons, skin, blood vessels, and nerves [47]. To further improve the bioactivity of the scaffolds, various types of strategies have been proposed to modify the scaffolds. Kartogenin, a small molecule drug that promotes cartilage lineage commitment of stem cells, has been conjugated with amphiphilic polyurethanes nanoparticles for leveraging the chondrogenic effect, but its oil solubility predisposes it to the exposure to the toxic organic solvents during the modification process [48]. Cartilage-decellularized matrix, has recently been considered as a chondrogenic material to be incorporated with synthetic degradable polymers for inducing chondrogenesis [42]. However, it is difficult to be homogenized or to be dissolved in organic solvents, making it an impossible material to be processed into biomimetic ECM-like structures on the nanoscale [29]. Besides, there are still immunological risks due to their exogenous sources from porcine or goat.

In this work, CS, the composition found in cartilage ECM was evaluated to improve the synthesis of the cartilage-specific matrix and to modulate the inflammatory microenvironment after injury [49]. Chondroitin sulphate, a negatively-charged polysaccharide broadly distributed in the cartilage, is involved in various physiological activities, such as cell growth and differentiation as well as the regulation of the Loading [MathJax]/jax/output/CommonHTML/jax.js echanical properties of CS may limit its applications for CTE. 
More targeted design is suggested to incorporate it with the other active substances for designing engineering cartilage scaffold $[52,53]$. In this study, CS cross-linked PLCL/SF scaffolds were successfully prepared by using EDC/NHS coupling chemistry, which exhibited considerable potential for cartilage regeneration in vitro and in vivo (Fig. 1). However, the introduction of CS increased the hydrophilicity of the scaffolds, leading to a more rapid increase in the thickness during gas foaming process, making it a challenge to develop 3D electrospun nanofibrous scaffolds with controllable size (Fig. 2). To achieve a precise control of 3D electrospun scaffolds, various approaches have been put forwarded. By using a conductive mold as a collector, Sun et al. [54] fabricated a 3D nanoyarn scaffold with hexagonal shape, which were mineralized for bone regeneration. Chen et al. [55] employed short nanofiber powder as bioinks for 3D printing of scaffolds with controllable pore size. Other advanced approaches, such as origami- and kirigami-based techniques may offer a modality by which electrospun membranes may be transformed into 3D structures [41]. Although the aforementioned studies proved to be a significant advancement in fabricating 3D scaffolds with accurate size, the superficial pores with lacking porous layered structures may compromise these approaches. In this study, by considering the cost and reproducibility, a simple mold made of a combination of a Teflon and glass was employed, which is not only easy to be assembled, but is also chemically inert, avoiding interference with the foaming process. After gas foaming by using this "confined expansion" molding technology, 3D scaffolds with customized thickness and multi-layered structure were generated (Fig. 3).

The high porosity is a fundamental characteristic that enables scaffolds to provide adequate space for cell infiltration. During the gas foaming process, bubbles converge within the nanofiber pores and exert pressure on the surrounding fibers, resulting in an increase in the porosity, which is macroscopically manifested as an increase in the volume and thickness of scaffolds. A highly porous scaffold with an interconnected pore network is required for uniform spatial distribution of cells and to minimize the diffusion-limiting effects on nutrients and waste products [45]. This is particularly essential for highdensity chondrocyte culture in vitro to produce clinically significant volume of cartilage tissues. Furthermore, high porosity and aligned topographical cues facilitate efficient intercellular contact, which has been associated with the high rates of the ECM synthesis [56]. After treatment with the foaming agent and freeze-drying, the 3D gas-foamed scaffolds retain their aligned nanofiber morphology with higher porosity, indicating their better performance over the nanofibrous membranes in promoting cell infiltration and cartilage-related ECM secretion. Furthermore, an ideal scaffold should be able to withstand the specific strength. The mechanical properties of 3DCSS were significantly better than that of 3DS in both tensile and compressive tests (Fig. 4), which may be due to the stronger hydrogen bonding between the CS as well as the formation of amide bonds between the amino groups and the carboxylic groups.

The biocompatibility and bioactivity of scaffolds are important issues which strongly affect the feasibility of cartilage regeneration. The current results showed that chondrocytes stably survived on all of the scaffolds, indicating good biocompatibility and low cytotoxicity of both 2D membranes and 3D gas-foamed scaffold. Notably, 3DCSS achieved most rapid proliferation of chondrocytes as compared to Loading [MathJax]/jax/output/CommonHTML/jax.js ge-like tissues along with the secretion of the cartilaginous 
matrix both in vitro and in vivo. The biochemical results of chondrocytes cultured on different samples reemphasized the favorable influence of 3DCSS groups on the chondrogenic phenotype in vitro (Fig. 5). This is ascribed to the reason that the 3DCSS scaffolds mimic the GAG-rich ECM of chondrocytes, which may provide the cultured cells with a niche-like microenvironment, allowing them to maintain the differentiated chondrogenic phenotype in vitro [57]. Although the mechanical properties of the scaffolds inevitably declined after gas foaming owing to the increased porosity and a loose structure, the 3DCSS showed improved mechanical parameters than that of the 3DS. This may help to present a stable 3D environment for the growth of chondrocytes and cartilage tissue regeneration. In addition to the improvements of the mechanical properties, the introduction of CS also played a crucial role in enhancing the bioactivity of scaffold. The precise role of CS in creating a chondro-inductive environment for the neocartilage regeneration is not very clear. Previous studies have shown that chondrocytes cultured on CSmodified chitosan membranes retained their phenotype and produced cartilage-specific matrix [57]. In another study, the introduction of CS downregulated the expression of genes encoding proteolytic enzymes involved in cartilage degradation, suggesting that CS may exert both chondro-protective and anti-inflammatory effects, which may prove to be beneficial for CTE applications [58]. Consistent with these previous results, 3DCSS scaffolds showed the bioactivity in promoting the maturation of chondrocytes and secretion of the cartilage-specific ECM as compared to the CS-free groups (Fig. 6). The existence of the CS might have multiple functions, such as the sequestration of the growth factors or direct interaction with the cells. The interaction of growth factors (GFs) with anionic domains in GAG, of which CS is a primary component, is well-known to play an essential role in morphogenesis and tissue homeostasis [59]. Growth factor-ECM interactions has been previously reported to prolong the half-life and activity of growth factors [25]; therefore it can be assumed that the sulfate domains of CS may interact with some of the GFs, thereby activating the required signaling that favor cartilage regeneration. Furthermore, it has been reported that CS possibly stimulates the synthesis of proteoglycans by inhibiting the synthesis of proteolytic enzymes and other factors that cause the cell apoptosis and cartilage matrix degradation [60]. This would explain the better potential of the 3DCSS scaffolds over other CS-free groups in reducing the synthesis of pro-inflammatory cytokines, such as IL-1 $\beta$ and TNF- $a$ (Fig. 7), thus attenuating inflammation and promoting cartilaginous tissue regeneration after the occurrence of joint injury.

\section{Conclusion}

In summary, we described a novel 3D CS-crosslinked biomimetic porous nanofibrous scaffolds with precise thickness via gas foaming in a pre-designed mold and subsequent freeze-drying for promoting cartilage regeneration and moderating joint inflammation. 3D gas-foamed scaffolds demonstrated low density, appropriate porosity and fast water absorption. Moreover, they preserved nano-topographical architecture with multilayered structures and stable mechanical properties. All of the scaffolds exhibited good cytocompatibility, while 3D gas-foamed scaffolds promoted seeding efficiency and proliferation of chondrocytes than that of 2DS. More importantly, biomimetic 3DCSS displayed good biological putrnmoc than thnea of the nthor arnunc ac evidenced by the formation of cartilage-specific ECM, Loading [MathJax]/jax/output/CommonHTML/jax.js

Page $17 / 30$ 
significant regeneration of articular cartilage in a rabbit model and less expression of pro-inflammatory factors both in vitro and in vivo. Moreover, the better mechanical and biological properties of 3DCSS were effective for the regeneration of the articular cartilage. Taken together, this strategy of designing biomimetic scaffolds as well as improving their performance by gas foaming may have broad implications for CTE applications.

\section{Declarations}

\section{Acknowledgement}

This research was supported by the Fundamental Research Funds for the Central Universities (2232019A3-07), National Nature Science Foundation of China (No. 81970091, 32050410286, 31771023, 3201101259), Science and Technology Commission of Shanghai Municipality (No.19441902600, 20S31900900, 20DZ2254900), Program of Shanghai Academic/Technology Research Leader (19XD1431100), and Sino German Science Foundation Research Exchange Center (M-0263). This project was also supported by Researchers Supporting Project Number (RSP-2021/65), King Saud University, Riyadh, Saudi Arabia.

\section{Authors' contributions}

YC: Investigation, Methodology, Formal analysis, Writing-original draft; WX: Investigation, Conceptualization, Data Curation; MS: Conceptualization, Review \& Editing; DS: Conceptualization, Data Curation; XX: Investigation, Conceptualization; ZY: Conceptualization, Data Curation; ME: Investigation, Conceptualization; HE: Investigation, Conceptualization; YM: Investigation, Conceptualization; YL: Conceptualization, Funding acquisition, Review \& editing; XM: Supervision, Funding acquisition, Review \& editing. YC and WX contributed equally to this work. All authors read and approved the final manuscript.

\section{Availability of data and materials}

The datasets used and analyzed during the current study are available from the corresponding author on reasonable request.

\section{Competing Interest}

The authors declare that they have no known competing financial interests or personal relationships that could have appeared to influence the work reported in this paper.

\section{References}

1. Lories RJ, Luyten FP. The bone-cartilage unit in osteoarthritis. Nat Rev Rheumatol [Internet]. Nature Publishing Group; 2011;7:43-9. Available from: http://dx.doi.org/10.1038/nrrheum.2010.197 
2. Mow VC, Ratcliffe A, Robin Poole A. Cartilage and diarthrodial joints as paradigms for hierarchical materials and structures. Biomaterials. 1992;13:67-97.

3. Makris EA, Gomoll AH, Malizos KN, Hu JC, Athanasiou KA. Repair and tissue engineering techniques for articular cartilage. Nat Rev Rheumatol [Internet]. Nature Publishing Group; 2015;11:21-34. Available from: http://dx.doi.org/10.1038/nrrheum.2014.157

4. Moran CJ, Pascual-Garrido C, Chubinskaya S, Potter HG, Warren RF, Cole BJ, et al. Restoration of articular cartilage. J Bone Jt Surg - Ser A. 2014;96:336-44.

5. Johnna ST, Antonios GM. Review: tissue engineering for regeneration of articular cartilage. Biomaterials. 2000;21:431-40.

6. Nukavarapu SP, Dorcemus DL. Osteochondral tissue engineering: Current strategies and challenges. Biotechnol Adv [Internet]. Elsevier Inc.; 2013;31:706-21. Available from:

http://dx.doi.org/10.1016/j.biotechadv.2012.11.004

7. Nesic $D$, Whiteside R, Brittberg M, Wendt $D$, Martin I, Mainil-Varlet P. Cartilage tissue engineering for degenerative joint disease. Adv Drug Deliv Rev. 2006;58:300-22.

8. Huey DJ, Hu JC, Athanasiou K a. Unlike Bone, Cartilage Regeneration Remains Elusive. Science (80- ). 2012;6933:917-21.

9. Chen Y, Sha M, Liu M, Morsi Y, Mo X. Advanced fabrication for electrospun three-dimensional nanofiber aerogels and scaffolds. Bioact Mater. 2020;5:963-79.

10. Blakeney BA, Tambralli A, Anderson JM, Andukuri A, Lim DJ, Dean DR, et al. Cell infiltration and growth in a low density, uncompressed three-dimensional electrospun nanofibrous scaffold. Biomaterials [Internet]. Elsevier Ltd; 2011;32:1583-90. Available from:

http://dx.doi.org/10.1016/j.biomaterials.2010.10.056

11. Jin D, Hu J, Xia D, Liu A, Kuang H, Du J, et al. Evaluation of a simple off-the-shelf bi-layered vascular scaffold based on poly(L-lactide-co- $\varepsilon$-caprolactone)/silk fibroin in vitro and in vivo. Int J Nanomedicine. 2019;14:4261-76.

12. Wu T, Zhang J, Wang Y, Sun B, Guo X, Morsi Y, et al. Development of dynamic liquid and conjugated electrospun poly(L-lactide-co-caprolactone)/collagen nanoyarns for regulating vascular smooth muscle cells growth. J Biomed Nanotechnol. 2017;13:303-12.

13. Boda SK, Chen S, Chu K, Kim HJ, Xie J. Electrospraying Electrospun Nanofiber Segments into Injectable Microspheres for Potential Cell Delivery. ACS Appl Mater Interfaces. 2018;10:25069-79.

14. Chen S, John J V., McCarthy A, Carlson MA, Li X, Xie J. Fast transformation of 2D nanofiber 
applications. Appl Phys Rev. AIP Publishing LLC; 2020;7.

15. Jiang J, Carlson MA, Teusink MJ, Wang H, MacEwan MR, Xie J. Expanding Two-Dimensional Electrospun Nanofiber Membranes in the Third Dimension by a Modified Gas-Foaming Technique. ACS Biomater Sci Eng. 2015;1:991-1001.

16. Jiang J, Chen S, Wang H, Carlson MA, Gombart AF, Xie J. CO2-expanded nanofiber scaffolds maintain activity of encapsulated bioactive materials and promote cellular infiltration and positive host response. Acta Biomater [Internet]. Acta Materialia Inc.; 2018;68:237-48. Available from: https://doi.org/10.1016/j.actbio.2017.12.018

17. Joshi MK, Pant HR, Tiwari AP, kim HJ, Park CH, Kim CS. Multi-layered macroporous three-dimensional nanofibrous scaffold via a novel gas foaming technique. Chem Eng J [Internet]. Elsevier B.V.; 2015;275:79-88. Available from: http://dx.doi.org/10.1016/j.cej.2015.03.121

18. Jing X, Li H, Mi HY, Liu YJ, Tan YM. Fabrication of fluffy shish-kebab structured nanofibers by electrospinning, $\mathrm{CO} 2$ escaping foaming and controlled crystallization for biomimetic tissue engineering scaffolds. Chem Eng J [Internet]. Elsevier; 2019;372:785-95. Available from:

https://doi.org/10.1016/j.cej.2019.04.194

19. Chen S, Carlson MA, Zhang YS, Hu Y, Xie J. Fabrication of injectable and superelastic nanofiber rectangle matrices ("peanuts") and their potential applications in hemostasis. Biomaterials [Internet]. Elsevier Ltd; 2018;179:46-59. Available from: https://doi.org/10.1016/j.biomaterials.2018.06.031

20. Jiang J, Li Z, Wang H, Wang Y, Carlson MA, Teusink MJ, et al. Expanded 3D Nanofiber Scaffolds: Cell Penetration, Neovascularization, and Host Response. Adv Healthc Mater. 2016;5:2993-3003.

21. Zhang K, Bai X, Yuan Z, Cao X, Jiao X, Li Y, et al. Layered nanofiber sponge with an improved capacity for promoting blood coagulation and wound healing. Biomaterials [Internet]. Elsevier; 2019;204:70-9. Available from: https://doi.org/10.1016/j.biomaterials.2019.03.008

22. Rao F, Yuan Z, Li M, Yu F, Fang X, Jiang B, et al. Expanded 3D nanofibre sponge scaffolds by gasfoaming technique enhance peripheral nerve regeneration. Artif cells, nanomedicine, Biotechnol [Internet]. Taylor \& Francis; 2019;47:491-500. Available from: https://doi.org/10.1080/21691401.2018.1557669

23. Wei W, Ma Y, Yao X, Zhou W, Wang X, Li C, et al. Advanced hydrogels for the repair of cartilage defects and regeneration. Bioact Mater [Internet]. KeAi Communications Co., Ltd; 2021;6:998-1011. Available from: https://doi.org/10.1016/j.bioactmat.2020.09.030

24. Foss C, Merzari E, Migliaresi C, Motta A. Silk fibroin/hyaluronic acid 3D matrices for cartilage tissue engineering. Biomacromolecules. 2013;14:38-47.

25. Varghese S, Hwang NS, Canver AC, Theprungsirikul P, Lin DW, Elisseeff J. Chondroitin sulfate based Loading [MathJax]/jax/output/CommonHTML/jax.js esenchymal stem cells. Matrix Biol. 2008;27:12-21. 
26. Kuang H, Wang Y, Shi Y, Yao W, He X, Liu X, et al. Biomaterials Construction and performance evaluation of Hep / silk-PLCL composite nanofiber small-caliber artificial blood vessel graft. Biomaterials. 2020;259.

27. Cao B, Yin J, Yan S, Cui L, Chen X, Xie Y. Porous Scaffolds Based on Cross-Linking of Poly(L-glutamic acid). Macromol Biosci. 2011;11:427-34.

28. Chen W, Chen S, Morsi Y, El-Hamshary H, El-Newhy M, Fan C, et al. Superabsorbent 3D Scaffold Based on Electrospun Nanofibers for Cartilage Tissue Engineering. ACS Appl Mater Interfaces. 2016;8:2441525 .

29. Xu Y, Li D, Yin Z, He A, Lin M, Jiang G, et al. Tissue-engineered trachea regeneration using decellularized trachea matrix treated with laser micropore technique. Acta Biomater [Internet]. Acta Materialia Inc.; 2017;58:113-21. Available from: http://dx.doi.org/10.1016/j.actbio.2017.05.010

30. Zhou G, Jiang H, Yin Z, Liu Y, Zhang Q, Zhang C, et al. In Vitro Regeneration of Patient-specific Earshaped Cartilage and Its First Clinical Application for Auricular Reconstruction. EBioMedicine [Internet]. The Authors; 2018;28:287-302. Available from: https://doi.org/10.1016/j.ebiom.2018.01.011

31. Xu Y, Duan L, Li Y, She Y, Zhu J, Zhou G, et al. Nanofibrillar Decellularized Wharton's Jelly Matrix for Segmental Tracheal Repair. Adv Funct Mater. 2020;30.

32. Xu Y, Xu Y, Bi B, Hou M, Yao L, Du Q, et al. A moldable thermosensitive hydroxypropyl chitin hydrogel for 3D cartilage regeneration in vitro and in vivo. Acta Biomater. 2020;108:87-96.

33. Chen Y, Xu W, Shafiq M, Tang J, Hao J, Xie X, et al. Three-dimensional porous gas-foamed electrospun nanofiber scaffold for cartilage regeneration. J Colloid Interface Sci [Internet]. Elsevier Inc.; 2021;603:94109. Available from: https://doi.org/10.1016/j.jcis.2021.06.067

34. Yan D, Zhou G, Zhou X, Liu W, Zhang WJ, Luo X, et al. The impact of low levels of collagen IX and pyridinoline on the mechanical properties of in vitro engineered cartilage. Biomaterials [Internet]. Elsevier Ltd; 2009;30:814-21. Available from: http://dx.doi.org/10.1016/j.biomaterials.2008.10.042

35. Zou Z, Wei M, Fang J, Dai W, Sun T, Liu Q, et al. Preparation of chondroitin sulfates with different molecular weights from bovine nasal cartilage and their antioxidant activities. Int J Biol Macromol [Internet]. Elsevier LTD; 2020;152:1047-55. Available from:

https://doi.org/10.1016/j.jjbiomac.2019.10.192

36. Almodóvar J, Place LW, Gogolski J, Erickson K, Kipper MJ. Layer-by-layer assembly of polysaccharidebased polyelectrolyte multilayers: A spectroscopic study of hydrophilicity, composition, and ion pairing. Biomacromolecules. 2011;12:2755-65.

37. Yu W, Wanka R, Finlay JA, Clarke JL, Clare AS, Rosenhahn A. Degradable hyaluronic acid/chitosan Loading [MathJax]/jax/output/CommonHTML/jax.js hg-release properties. Biofouling [Internet]. Taylor \& Francis; 
2020;0:1-22. Available from: https://doi.org/10.1080/08927014.2020.1846725

38. Xue J, Wu T, Dai Y, Xia Y. Electrospinning and electrospun nanofibers: Methods, materials, and applications. Chem Rev. American Chemical Society; 2019;119:5298-415.

39. Chen W, Xu Y, Liu Y, Wang Z, Li Y, Jiang G, et al. Three-dimensional printed electrospun fiber-based scaffold for cartilage regeneration. Mater Des [Internet]. The Authors; 2019;179:107886. Available from: https://doi.org/10.1016/j.matdes.2019.107886

40. Si Y, Yu J, Tang X, Ge J, Ding B. Ultralight nanofibre-assembled cellular aerogels with superelasticity and multifunctionality. Nat Commun. Nature Publishing Group; 2014;5:5802.

41. Song J, Zhu G, Gao H, Wang L, Li N, Shi X, et al. Origami meets electrospinning: a new strategy for 3D nanofiber scaffolds. Bio-Design Manuf [Internet]. Springer Singapore; 2018;1:254-64. Available from: https://doi.org/10.1007/s42242-018-0027-9

42. Chen W, Xu Y, Li Y, Jia L, Mo X, Jiang G, et al. 3D printing electrospinning fiber-reinforced decellularized extracellular matrix for cartilage regeneration. Chem Eng J [Internet]. Elsevier; 2019;122986. Available from: https://doi.org/10.1016/j.cej.2019.122986

43. Chen S, Wang H, McCarthy A, Yan Z, Kim HJ, Carlson MA, et al. Three-Dimensional Objects Consisting of Hierarchically Assembled Nanofibers with Controlled Alignments for Regenerative Medicine. Nano Lett. 2019;19:2059-65.

44. Shafiq M, Kong D, Kim SH. SDF-1 a peptide tethered polyester facilitates tissue repair by endogenous cell mobilization and recruitment. J Biomed Mater Res - Part A. 2017;105:2670-84.

45. Lin YJ, Liao CJ, Chen CF, Tsai W. Porous biodegradable polymer scaffolds for cartilage tissue engineering. Third Smith Nephew Int Symp - Transl Tissue Eng into Prod. 2002;122.

46. Çalamak S, Erdoğdu C, Özalp M, Ulubayram K. Silk fibroin based antibacterial bionanotextiles as wound dressing materials. Mater Sci Eng C. 2014;43:11-20.

47. Xie X, Chen $Y$, Wang $X$, Xu X, Shen $Y$, Khan A ur R, et al. Electrospinning nanofiber scaffolds for soft and hard tissue regeneration. J Mater Sci Technol [Internet]. Elsevier Ltd; 2020;59:243-61. Available from: https://doi.org/10.1016/j.jmst.2020.04.037

48. Fan W, Li J, Yuan L, Chen J, Wang Z, Wang Y, et al. Intra-articular injection of kartogenin-conjugated polyurethane nanoparticles attenuates the progression of osteoarthritis. Drug Deliv [Internet]. Informa Healthcare USA, Inc; 2018;25:1004-12. Available from: https://doi.org/10.1080/10717544.2018.1461279

49. Reginster JY, Veronese N. Highly purified chondroitin sulfate: a literature review on clinical efficacy and pharmacoeconomic aspects in osteoarthritis treatment. Aging Clin Exp Res [Internet]. Springer 
50. lovu M, Dumais G, du Souich P. Anti-inflammatory activity of chondroitin sulfate. Osteoarthr Cartil. 2008;16:14-8.

51. Uebelhart D. Clinical review of chondroitin sulfate in osteoarthritis. Osteoarthr Cartil. 2008;16:19-21.

52. Shen Q, Zhang C, Mo H, Zhang H, Qin X, Li J, et al. Fabrication of chondroitin sulfate calcium complex and its chondrocyte proliferation in vitro. Carbohydr Polym [Internet]. Elsevier Ltd; 2021;254:117282. Available from: https://doi.org/10.1016/j.carbpol.2020.117282

53. A V T, Mohanty S, Dinda AK, Koul V. Fabrication and evaluation of gelatin/hyaluronic acid/chondroitin sulfate/asiatic acid based biopolymeric scaffold for the treatment of second-degree burn wounds - Wistar rat model study. Biomed Mater. 2020;15.

54. Sun B, Li J, Liu W, Aqeel BM, El-Hamshary H, Al-Deyab SS, et al. Fabrication and characterization of mineralized P(LLA-CL)/SF three-dimensional nanoyarn scaffolds. Iran Polym J (English Ed. 2014;24:2940.

55. Chen W, Xu Y, Liu Y, Wang Z, Li Y, Jiang G, et al. Three-dimensional printed electrospun fiber-based scaffold for cartilage regeneration. Mater Des [Internet]. Elsevier Ltd; 2019;107886. Available from: https://linkinghub.elsevier.com/retrieve/pii/S0264127519303247

56. Puelacher WC, Kim SW, Vacanti JP, Schloo B, Mooney D, Vacanti CA. Tissue-engineered growth of cartilage: the effect of varying the concentration of chondrocytes seeded onto synthetic polymer matrices. Int J Oral Maxillofac Surg. 1994;23:49-53.

57. Sechriest VF, Miao YJ, Niyibizi C, Westerhausen-Larson A, Matthew HW, Evans CH, et al. GAGaugmented polysaccharide hydrogel: A novel biocompatible and biodegradable material to support chondrogenesis. J Biomed Mater Res. 2000;49:534-41.

58. Legendre F, Baugé $C$, Roche R, Saurel AS, Pujol JP. Chondroitin sulfate modulation of matrix and inflammatory gene expression in IL-1 $\beta$-stimulated chondrocytes - study in hypoxic alginate bead cultures. Osteoarthr Cartil. 2008;16:105-14.

59. Hubbell JA. Materials as morphogenetic guides in tissue engineering. Curr Opin Biotechnol. 2003;14:551-8.

60. Muzzarelli RAA, Greco F, Busilacchi A, Sollazzo V, Gigante A. Chitosan, hyaluronan and chondroitin sulfate in tissue engineering for cartilage regeneration: A review. Carbohydr Polym [Internet]. Elsevier Ltd.; 2012;89:723-39. Available from: http://dx.doi.org/10.1016/j.carbpol.2012.04.057

\section{Figures}




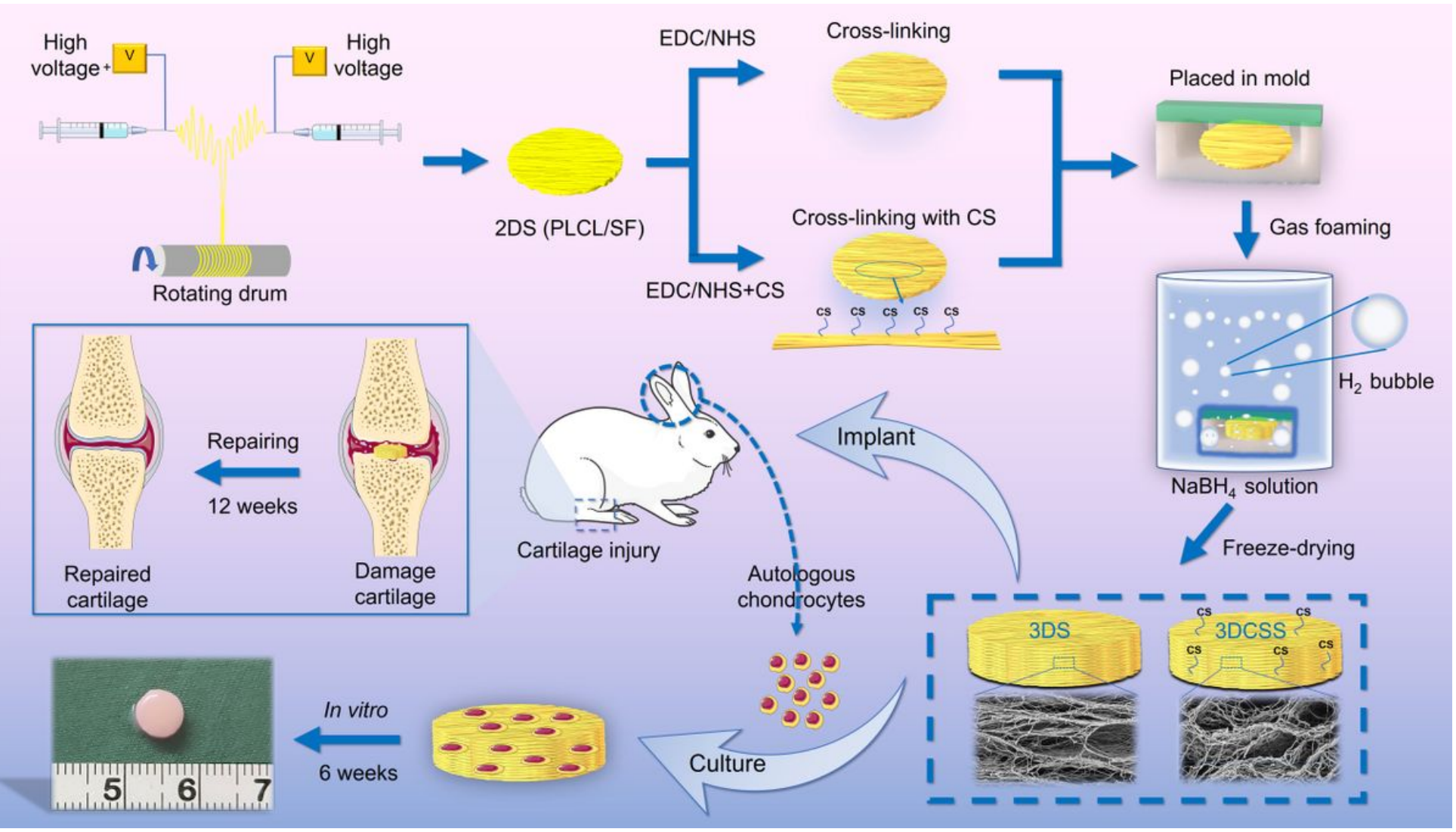

\section{Figure 1}

Schematic illustration of the preparation of 2DS, 3DS, and 3DCSS scaffolds for CTE. 2DS were fabricated by conjugate electrospinning, crosslinked via CS, and expanded by using gas foaming. The bioactivity of membranes was assessed in vitro and in vivo. 

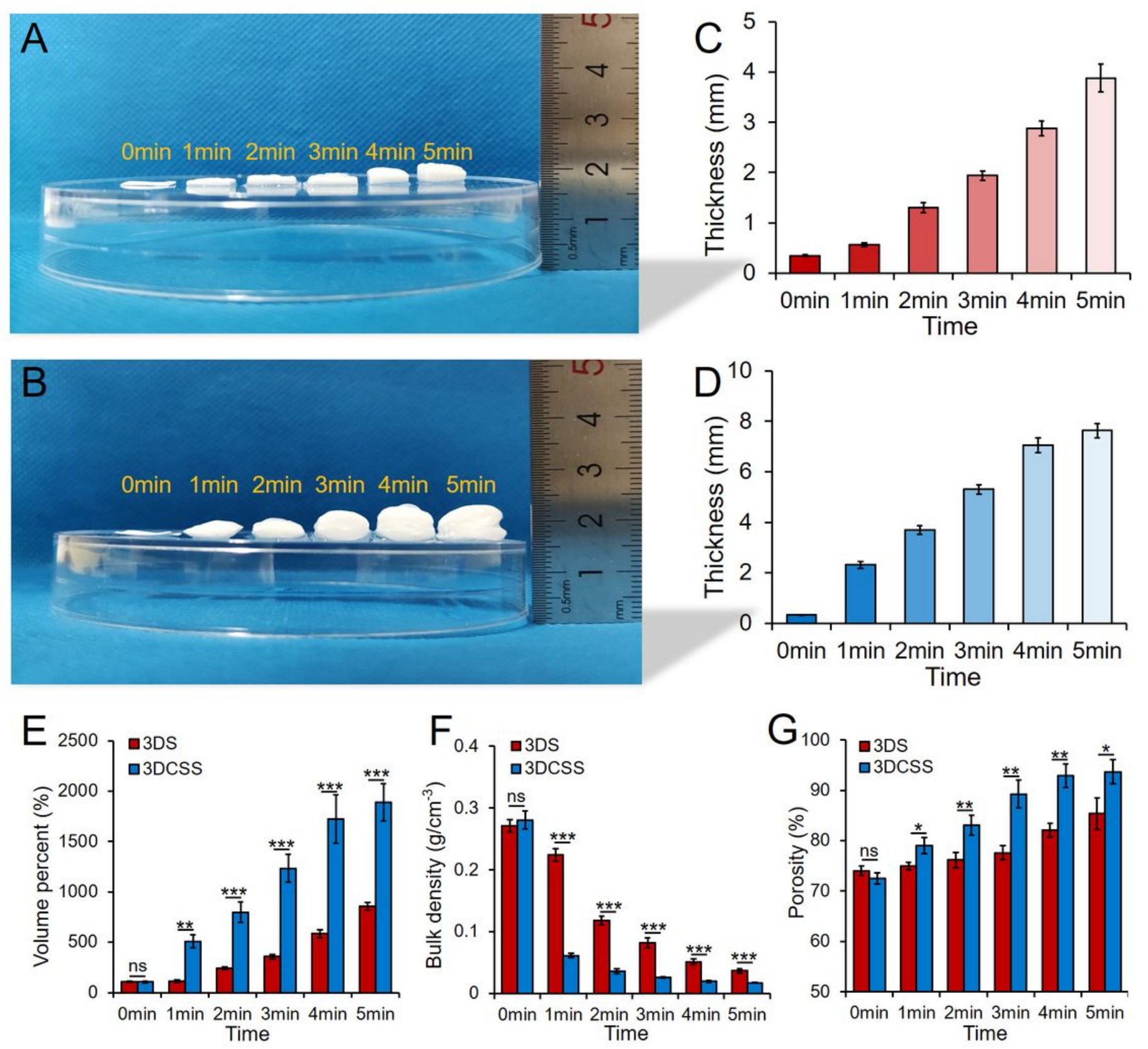

\section{Figure 2}

Photographs of 3DS (A) and 3DCSS (B) before and after expansion for different time intervals. Thickness of the 3DS (C) and 3DCSS (D) for different time points. The volume expansion (E), bulk density (F) and porosity $(G)$ of 3DS and 3DCSS for different time periods. Each value represents the mean $\pm S D(n=3)$. * $p<0.05, * * p<0.01, * * * p<0.001$. 

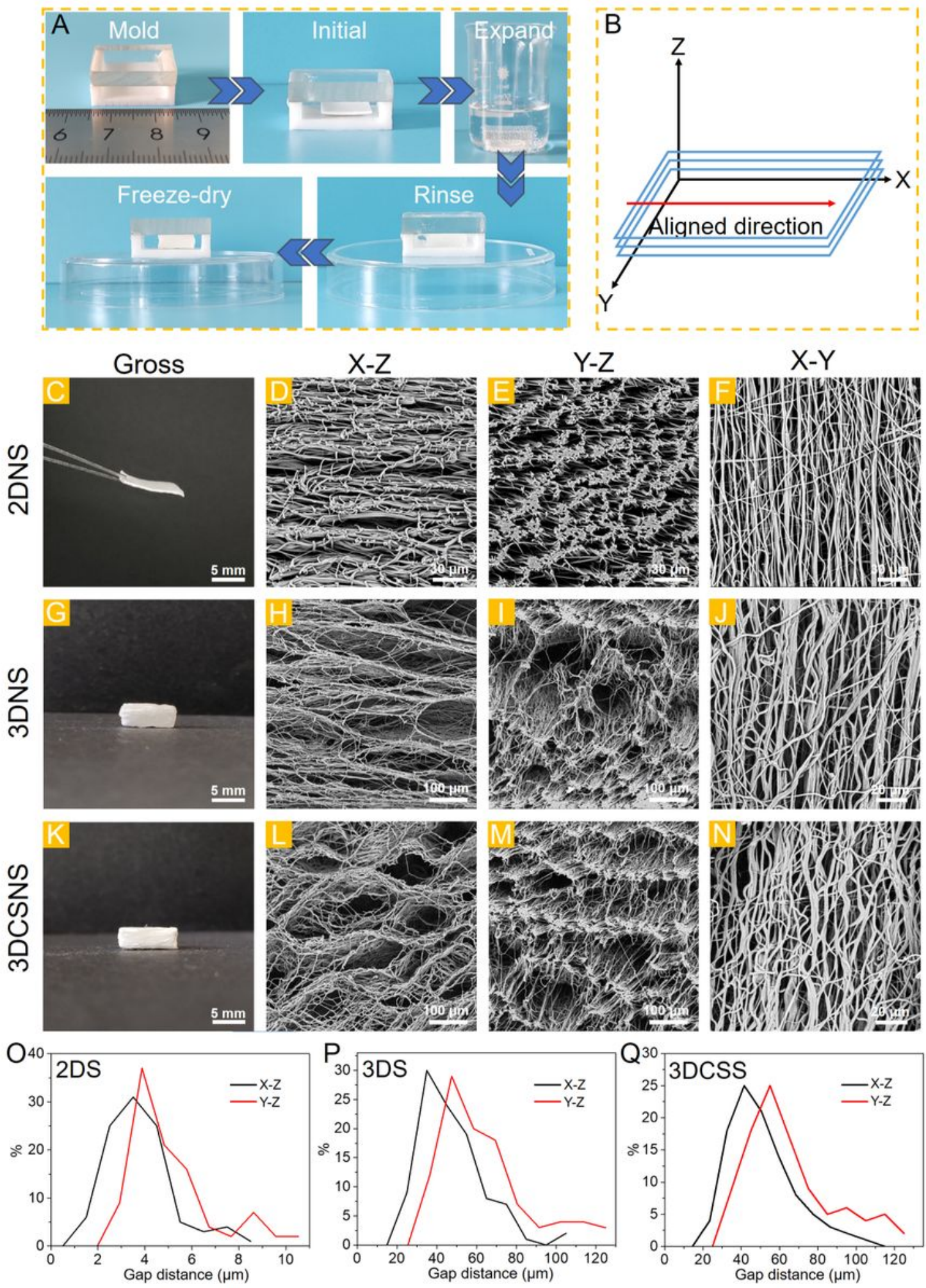

\section{Figure 3}

Fabrication and characterization of gas foamed scaffolds with tailored size. (A) Illustration of the preparation of gas-foamed scaffolds by using a pre-designed mold with $3 \mathrm{~mm}$ height. (B) Illustration of the alignment direction of the scaffold. Digital photographs of 2DS (C), 3DS (G) and 3DCSS (K). SEM micrographs of 2DS $(D-F), 3 D S(H-J)$, and 3DCSS $(L-N)$. Distribution of the gap distance between the Loading [MathJax]/jax/output/CommonHTML/jax.js different directions. 

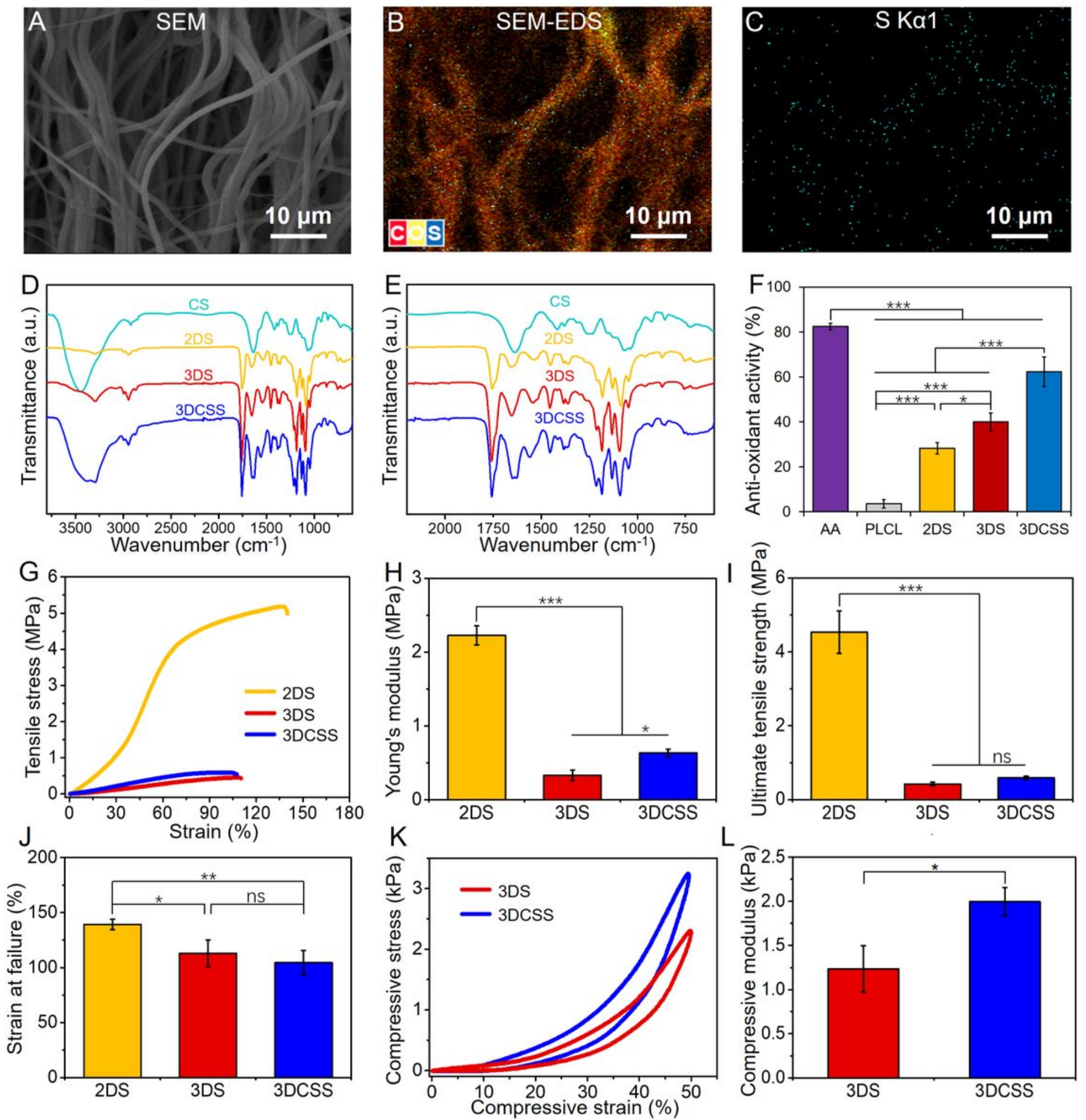

Figure 4

Representative elemental mapping of the 3DCSS scaffolds including SEM image (A), the EDS image (B), and the distribution of sulfur (C). (D-E) FTIR spectra of CS, 2DS, 3DS, and 3DCSS. (F) Free radical inhibition (antioxidant activity) of PLCL, 2DS, 3DS and 3DCSS by DPPH assay. Representative tensile stress-strain curves $(\mathrm{G})$, Young's modulus $(\mathrm{H})$, ultimate tensile strength $(\mathrm{I})$ and elongation at break $(\mathrm{J})$ of 
2DS, 3DS and 3DCSS. Representative compressive stress-strain curves (K) and compressive modulus (L) of 3DS and 3DCSS. Each value represents the mean $\pm S D(n=3)$. ${ }^{*} p<0.05,{ }^{*} p<0.01,{ }^{*} *{ }^{*} p<0.001$.
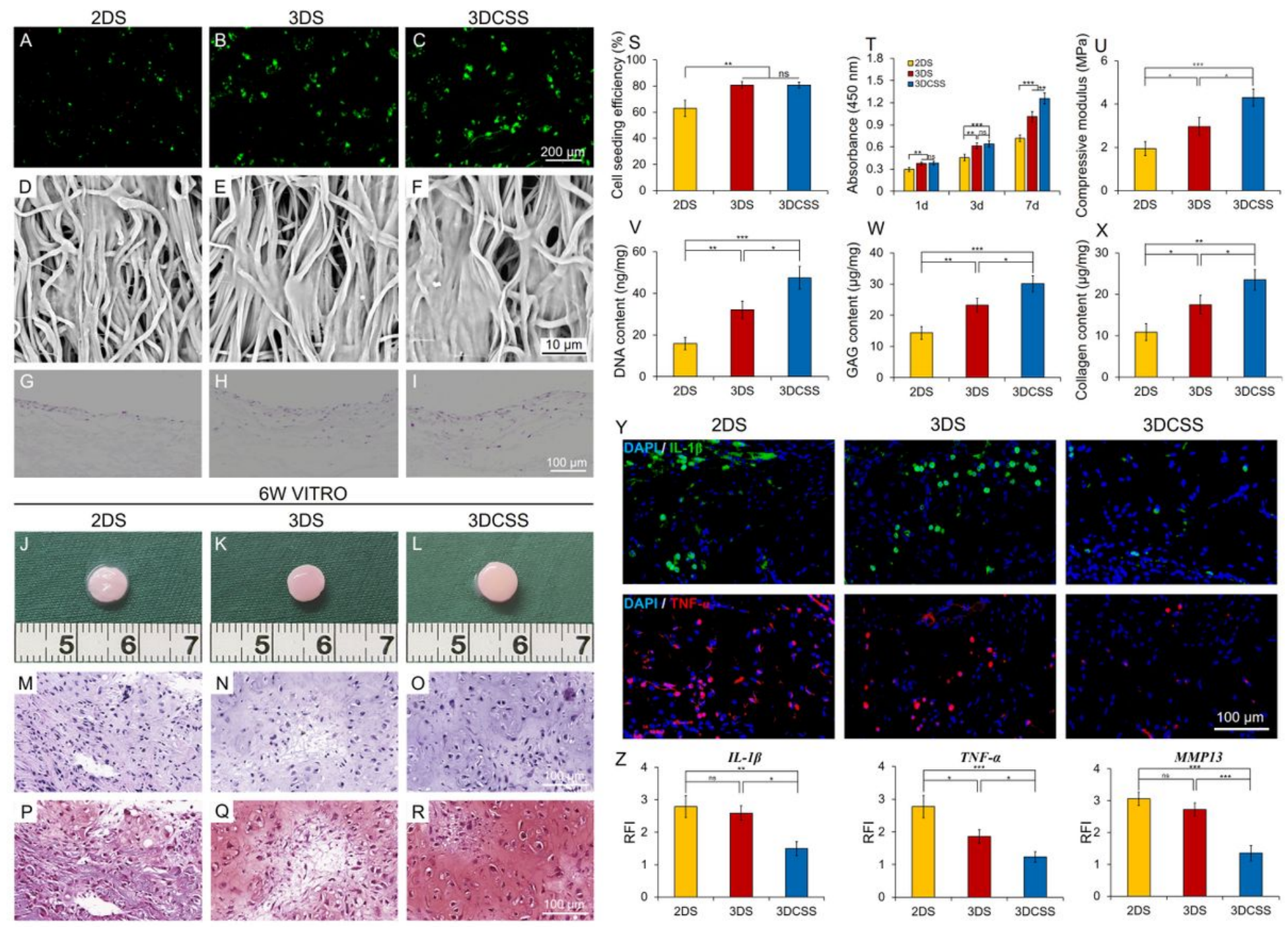

Figure 5

Cytocompatibility and chondrogenic activity of 2DS, 3DS and 3DCSS in vitro. Live/dead staining of chondrocytes seeded on 2DS (A), 3DS (B), and 3DCSS (C) after $24 \mathrm{~h}$ of culture. SEM images of chondrocytes on 2DS (D), 3DS (E), and 3DCSS (F) after 5 days of culture. H\&E staining of infiltrated chondrocytes in 2DS (G), 3DS (H), and 3DCSS (I) after 7 days of culture. Macroscopic images (J-L), H\&E staining $(M-O)$, and Safranin-O staining $(P-R)$ of engineered neo-cartilage after 6 weeks of culture in vitro. (S) Cell seeding efficiency of 2DS, 3DS, and 3DCSS after $4 \mathrm{~h}$ of culture $(n=3)$. (T) Proliferation of chondrocytes on 2DS, 3DS, and 3DCSS after 1, 3, 7 days of culture $(n=4)$. Biochemical and biomechanical analysis of compressive modulus (U), DNA content $(\mathrm{V}), \mathrm{GAG}$ content $(\mathrm{W})$, and collagen content $(X)$ of cell-scaffold constructs after 6 weeks of culture in vitro $(n=3)$. $(Y)$ Immunofluorescence staining for IL-1 $\beta$ and TNF- $\alpha$ in chondrocytes cultured on the different scaffolds with IL-1 $\beta$ treatment. (Z) Real-time PCR detection of inflammatory factors, including IL-1 $\beta$, TNF- $\alpha$, and MMP-13 in chondrocytes 
cultured on different scaffolds $(n=3)$. RFI = Relative fold induction. Each value represents the mean \pm SD. ${ }^{*} p<0.05,{ }^{*} p<0.01, * \star * p<0.001$.
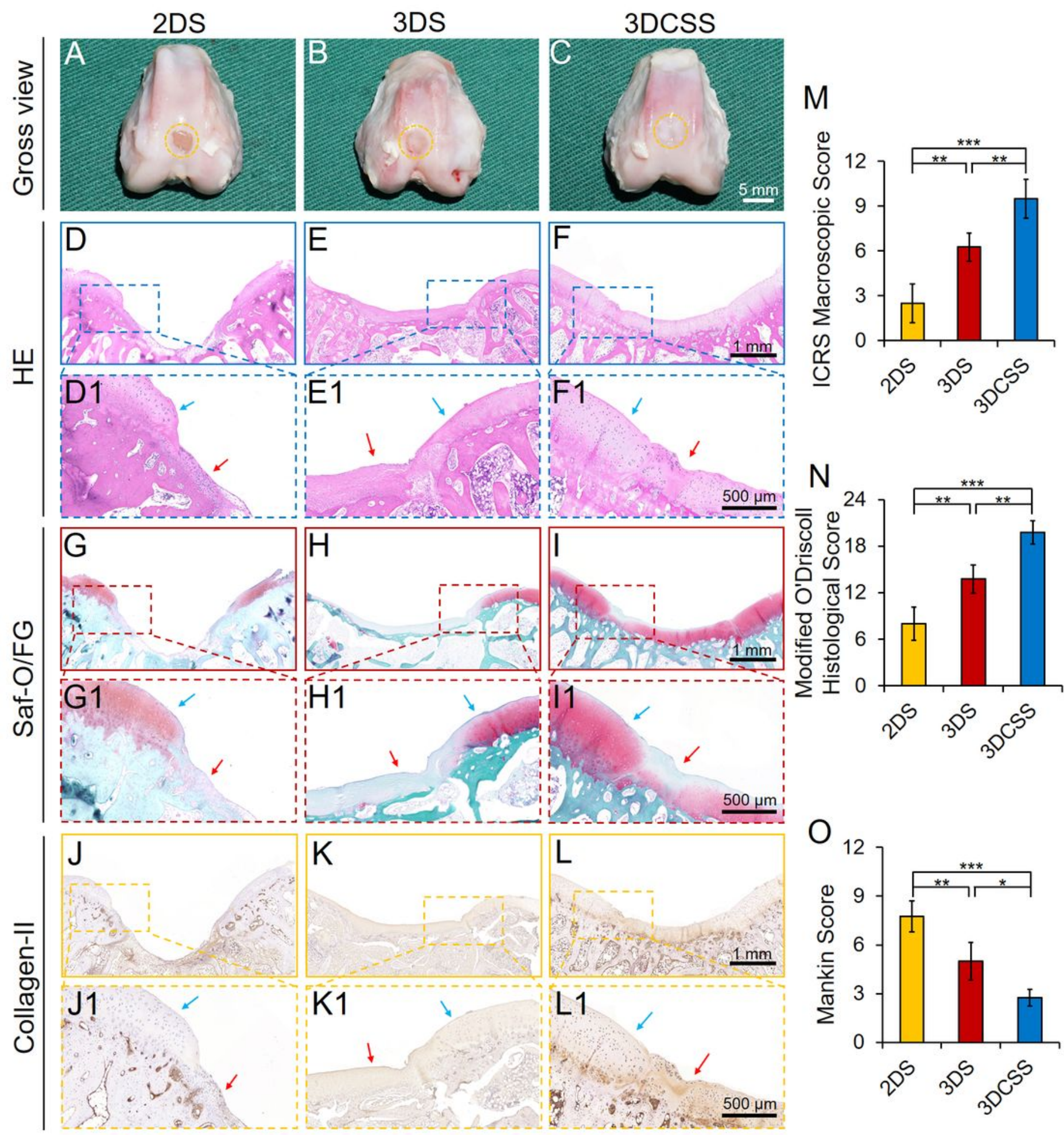

\section{Figure 6}

(A-C) Macroscopic images of cartilage joints of cartilage defects regions at 12 weeks post-surgery, $\mathrm{H} \& \mathrm{E}$ (D-F, D1-F1), Saf-O/FG staining (G-I, G1-I1), and type II collagen (J-L, J1-L1) immunohistochemical Loading [MathJax]/jax/output/CommonHTML/jax.js ects in different groups at 12 weeks after surgery. The blue 
arrows point toward the intact cartilage area, and the red arrows indicate the cartilage defect area. ICRS macroscopic assessment score $(\mathrm{M})$, modified O'Driscoll histological score $(\mathrm{N})$ and Mankin score $(\mathrm{O})$ of the repaired tissue. Each value represents the mean $\pm S D(n=4) .{ }^{*} p<0.05,{ }^{* *} p<0.01,{ }^{* *} p<0.001$.

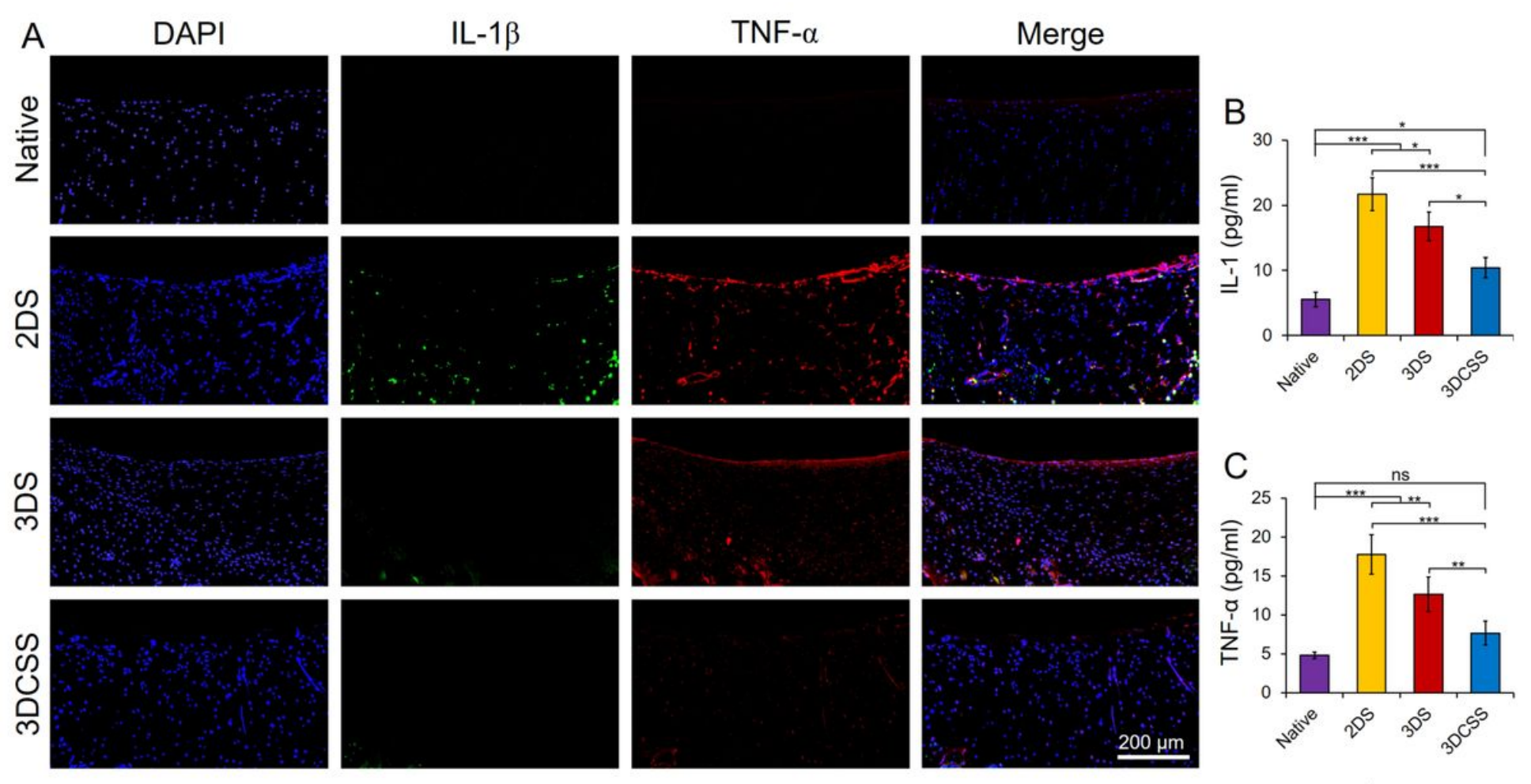

Figure 7

(A) Immunofluorescent staining for IL-1 $\beta$ and TNF- $\alpha$ of the defect regions 12 weeks post-surgery. Quantification of concentration of IL-1 $\beta$ (B) and TNF- $\alpha$ (C) in the joint fluid using ELISA kit. Each value represents the mean $\pm S D(n=4) .{ }^{*} p<0.05,{ }^{* *} p<0.01,{ }^{* \star *} p<0.001$.

\section{Supplementary Files}

This is a list of supplementary files associated with this preprint. Click to download.

- Fig.S1.jpg

- Supplementaryinformation.docx

- Fig.S2.jpg

- Fig.S3.jpg

- Fig.S4.jpg

- Graphicalabstract.jpg 